\title{
Desafios para a realização da campanha de vacinação contra a COVID-19 no Brasil
}

Diante da rápida disseminação da COVID-19 em todos os continentes, no dia 30 de janeiro de 2020 a Organização Mundial da Saúde (OMS) declarou o novo surto de coronavírus (classificado como SARS-CoV-2) uma emergência de saúde pública de interesse internacional, o mais alto nível de alarme. Dentre as recomendações foram propostas a aceleração de vacinas, medidas terapêuticas e diagnósticos 1 .

Nesse contexto, foi desencadeada uma corrida pelo desenvolvimento de uma vacina. Cerca de 200 projetos de desenvolvimento estão registrados na OMS, dos quais 13 estão na fase 3 para a avaliação de eficácia, a última etapa antes da aprovação pelas agências reguladoras e posterior imunização da população ${ }^{2}$. A existência de tantos projetos já chegando na fase final dos testes, após a confirmação dos primeiros casos de COVID-19, só está sendo possível em função do gigantesco investimento feito pelos governos dos países desenvolvidos, das empresas farmacêuticas, inclusive trabalhando em parceria entre si, bem como de instituições não governamentais na busca de vacinas seguras e eficazes.

Além das plataformas usualmente conhecidas, como as vacinas de vírus inativados, atenuados, subunitárias proteicas, recombinantes e vetores virais, novas tecnologias de ácidos nucleicos (DNA e RNAm) estão sendo utilizadas 2.

Outra medida inédita que vem sendo adotada foi a criação do Covax Facility, ação liberada pela OMS, que tem por objetivo acelerar o desenvolvimento e a fabricação de vacinas contra a COVID-19 para garantir o acesso justo e equitativo para todos os países do mundo, sendo que mais de 170 países já aderiram a esta estratégia, inclusive o Brasil. Da iniciativa Covax Facility, o Ministério da Saúde terá direito a uma reserva de 40 milhões de doses 3 .

Na busca por garantir mais doses para a população brasileira, três acordos de transferência de tecnologia foram assinados no país: um do Instituto de Tecnologia em Imunobiológicos da Fundação Oswaldo Cruz (Bio-Manguinhos/Fiocruz)/Ministério da Saúde com o laboratório AstraZeneca ${ }^{4}$, que está trabalhando em parceria com a Universidade Oxford (Reino Unido), que estabeleceu o fornecimento inicial de 100 milhões de doses; outro do Instituto Butantan do Estado de São Paulo com a empresa Sinovac, China (Coronavac) 5 , garantindo o fornecimento de 46 milhões de doses; e o último do Instituto de Tecnologia do Paraná (TECPAR) do Estado do Paraná com o Instituto Gamaleya, Rússia (Sputinik V) 6,
1 Pesquisadora independente, Brasília, Brasil. 
ainda sem informações sobre o quantitativo que será disponibilizado. No entanto, até o início de dezembro de 2020 não havia nenhum contrato firmado de fornecimento de vacinas por meio desses dois últimos laboratórios ao Ministério da saúde, que divulgou nos meios de comunicação que estava se reunindo com as farmacêuticas Pfizer, Janssen, Moderna, Bharat Biotech e com o Fundo Russo de Investimento Direto (RDIF) e aguardava maiores informações sobre o andamento dos resultados das pesquisas e liberação das mesmas pelas agências reguladores para a decisão quanto a novas aquisições 7 .

Apenas a parceria da Fiocruz estava sendo financiada pelo Ministério da Saúde, sugerindo que no primeiro momento somente as doses entregues à Fiocruz, além daquelas reservadas pelo Covax, farão parte da estratégia de vacinação do Programa Nacional de Imunizações (PNI). Esse será o primeiro desafio para as ações de vacinação, pois caso o Ministério da Saúde somente faça a aquisição da vacina de Oxford e do Covax, possivelmente haverá a aquisição de vacinas pelas Unidades Federadas, que poderão definir estratégias de vacinação diferentes daquelas que serão traçadas pelo Ministério da Saúde.

Nesse contexto, espera-se que no primeiro semestre de 2021, após a aprovação do uso das vacinas pelas agências reguladoras (no Brasil, a Agência Nacional de Vigilância Sanitária - Anvisa), o país já comece a receber as primeiras doses para serem utilizadas no território nacional. Esse será outro grande desafio, uma vez que, apesar de toda a aceleração do desenvolvimento vista até o momento, ainda existem muitas lacunas no conhecimento, impondo enorme dificuldade para se organizar o plano de vacinação.

As empresas Pfizer e Moderna e o Instituto Gamaleya divulgaram preliminarmente os resultados dos estudos da fase 3, na qual a eficácia das suas vacinas apresentou resultados acima de 90\%, sem efeitos adversos graves, demonstrando também a segurança destes imunobiológicos. Os resultados da análise de eficácia primária provisória da AstraZeneca apontam para uma eficácia de $62,1 \%$ para os participantes que receberam duas doses padrão e de $90 \%$ para aqueles que receberam primeiro meia dose e após um mês uma dose completa. Esses resultados são promissores uma vez que neste momento de urgência a OMS definiu que uma vacina com proteção acima de $50 \%$ será aceitável 8,9 .

Ainda não é possível saber se as vacinas irão induzir memória imunológica de longa duração, o que vai definir se haverá necessidade ou não de revacinação na população-alvo estabelecida. A maioria dos estudos foi realizada em populações acima de 18 anos, portanto, as vacinas não poderão ser usadas em crianças, adolescentes, além das gestantes e lactantes. Nesse sentido, é fundamental que o Ministério da Saúde planeje a realização de estudos complementares tanto para avaliar a efetividade da vacina, após a sua utilização na população-alvo definida pelo PNI, bem como o tempo de persistência de memória imunológica das diferentes vacinas que possam vir a ser utilizadas no país, além da eficácia da vacina em outros grupos não incluídos nos estudos da fase 3 , visando a realizar a expansão da vacinação na população brasileira.

A maioria das vacinas que chegou à fase 3 terá um esquema vacinal com duas doses, devendo ser aplicadas entre 14 a 29 dias após a aplicação da primeira dose 2, o que exigirá um enorme esforço e organização dos serviços de saúde para garantir a adesão do elevado contingente populacional a ser vacinado em um curto prazo, paras as duas doses. Isso também exigirá a identificação da pessoa vacinada nos postos de vacinação, havendo a necessidade da criação de um sistema nominal que seja simplificado e que consiga inserir os dados de forma oportuna, para acompanhar a evolução da vacinação. Ao mesmo tempo, será necessária a implementação da vigilância de eventos adversos pós-vacinação ativa e de 
forma oportuna, visando a garantir a segurança da vacinação durante todo o processo. Outro importante monitoramento que deverá ser realizado, após o início da vacinação, será o das gestantes que forem vacinadas inadvertidamente, ou seja, no momento da vacinação não sabiam que já estavam grávidas, portanto, deverão ser acompanhadas para avaliar a segurança da vacinação no período gestacional. Esta ação é fundamental, pois ao fazer este monitoramento e se provar que a vacinação foi segura, posteriormente a vacina poderá ser liberada para a aplicação em mulheres grávidas, uma vez que elas um importante grupo de risco para o COVID-19.

Por não haver estudos que indiquem se será possível a aplicação simultânea das vacinas contra a COVID-19 com outras vacinas, caso a vacinação seja realizada no mesmo período da campanha nacional de vacinação contra influenza a organização logística destas duas campanhas será outro enorme desafio, desde o armazenamento deste grande quantitativo de vacinas (a campanha de influenza tem como população-alvo 75 milhões de pessoas), seja em ter equipes suficientes para realizar as duas campanhas ao mesmo tempo, com populações-alvo distintas (crianças, gestantes e puérperas, por exemplo, não serão contemplados na campanha de vacinação contra a COVID-19), sem falar na necessidade de equipes para a manutenção das ações de rotina de todas as vacinas incluídas no Calendário Nacional de Vacinação.

As vacinas são produtos termolábeis, ou seja, produtos que podem se alterar ou se transformar quando expostos a variações da temperatura, razão pela qual é indispensável mantê-los em condições capazes de preservar as características de produção até o momento da aplicação na população-alvo, de modo a garantir a proteção preconizada. Para tanto, é fundamental haver uma rede de frio estruturada desde o laboratório produtor até a sala de vacinação, com responsabilidades definidas pelo recebimento, guarda e distribuição dos imunobiológicos. A rede de frio do PNI está organizada para receber produtos em temperaturas de $2^{\circ} \mathrm{C}$ a $8^{\circ} \mathrm{C}$. As vacinas de DNA e RNAm necessitam de armazenamento entre $-20^{\circ} \mathrm{C} \mathrm{e}-70^{\circ} \mathrm{C}$. Caso o PNI inclua essas vacinas no rol de produtos a serem disponibilizados nas salas de vacinação será necessária uma estruturação dessa rede, pois atualmente ela não tem capacidade tanto de armazenamento quanto de transporte destes produtos.

Outro desafio será o preço dessas novas vacinas e o impacto no orçamento do PNI para a aquisição desses produtos. A vacina da Oxford/AstraZeneca custará entre USD 3 e USD 4 por dose e as demais custarão em torno de USD 10 até USD 37 9. Essa diferença de preços poderá ser um empecilho para a incorporação dessas vacinas nos PNI dos países de baixo e médio ingresso. Como a AstraZeneca não terá a capacidade de atender a demanda mundial, caso os países queiram fazer uma campanha mais ostensiva precisarão lançar mão dessas vacinas de elevado custo financeiro.

Será necessária a definição e priorização dos grupos a serem vacinados, elencados com base no risco de adoecer, ter complicações e óbito: portadores de doenças crônicas, como câncer, diabetes, doenças cardiovasculares, doença renal, doença respiratória, enfermidades hematológicas, obesidade e pessoas acima de 60 anos. Os profissionais de saúde, por estarem na linha de frente do cuidado dos pacientes com COVID-19, possivelmente serão os primeiros a ser vacinados. Outros grupos deverão ser incluídos na estratégia de vacinação na medida em que houver disponibilidade de vacinas como os indígenas, quilombolas, população ribeirinha e privada de liberdade, professores, entre outros trabalhadores considerados como essenciais. 
Nesse sentido, é de extrema relevância a definição de uma estratégia de comunicação eficiente para esclarecer a população por que determinado grupo será vacinado e outro não, ou mesmo entre os grupos priorizados, porque a vacinação acontecerá em etapas e estas deverão ser seguidas para evitar uma corrida aos postos, o que poderá gerar aglomerações e possível desabastecimento. Uma vez que a vacinação ocorrerá por etapas, a medida em que as vacinas forem sendo entregues será fundamental a articulação dos vários setores da sociedade para a mobilização da população, principalmente naqueles estados que irão adquirir vacinas por conta própria. Ao mesmo tempo, essa comunicação deverá buscar estratégias para o enfrentamento aos grupos antivacina e às fake news que já estão circulando nas redes sociais, evitando que a população hesite em ser vacinada e garanta a adesão à vacinação.

Por fim, o PNI tem larga experiência em organizar campanhas de vacinação em massa, atingindo elevadas coberturas vacinais e o seu objetivo que é proteger a saúde da população definida nessas estratégias. Ao se atingir elevadas coberturas vacinais, além de reduzir casos de doença na população-alvo estabelecida para a vacinação, contribui para a diminuição da circulação de agentes infecciosos nas comunidades, impactando positivamente na saúde daqueles que não serão vacinados, uma vez que passam a estar protegidos indiretamente (imunidade coletiva ou de rebanho) 8,10. Portanto, a importância da vacinação não está somente na proteção individual, mas também porque ela evita a propagação em massa de doenças que podem levar à morte ou a sequelas graves, comprometendo a qualidade de vida e de saúde da população em geral.

A pandemia de COVID-19 vem produzindo repercussões não apenas de ordem biomédica e epidemiológica em escala global, mas também repercussões e impactos sociais, econômicos, políticos, culturais e históricos sem precedentes na história recente das epidemias. Dessa forma, será de extrema relevância que se tenha um plano nacional de vacinação para organizar toda a logística de execução da campanha, visando a que ela seja exitosa independentemente de que instrumentos ou fontes de recursos sejam utilizados para a aquisição de todos os tipos de vacinas que estarão disponíveis no território nacional. 


\section{Informação adicional}

ORCID: Carla Magda Allan Santos Domingues (0000-0003-1463-4939).
1. World Health Organization. Timeline: WHO response COVID-19. https://www.who. int/emergencies/diseases/novel-coronavi rus-2019/interactive-timeline (acessado em 02/Dez/2020).

2. World Health Organization. Draft landscape of COVID-19 candidate vaccines - 2 December 2020. https://www.who.int/publications/m/ item/draft-landscape-of-covid-19-candidatevaccines (acessado em 02/Dez/2020).

3. Presidência da República. Presidente Bolsonaro edita medidas provisórias que possibilitam adesão à Covax Facility. https://www.gov.br/ secretariageral/pt-br/noticias/2020/setem bro/presidente-bolsonaro-edita-medidas-pro visorias-que-possibilitam-adesao-a-covax-fa cility (acessado em 03/Dez/2020).

4. Portal Fiocruz. Covid-19: Fiocruz firmará acordo para produzir vacina da Universidade de Oxford. https://portal.fiocruz.br/noticia/ covid-19-fiocruz-firmara-acordo-para-pro duzir-vacina-da-universidade-de-oxford (acessado em 03/Dez/2020).

5. Instituto Butantan. Vacina contra a COVID-19. https://vacinacovid.butantan.gov.br/vacinas (acessado em 03/Dez/2020).

6. Tecpar: Instituto de Tecnologia do Paraná. Vacina russa será submetida à Anvisa até o fim de setembro. http://www.tecpar.br/Noticia/ Vacina-russa-sera-submetida-Anvisa-ate-ofim-de-setembro (acessado em 03/Dez/2020).
7. Oliveira M. Ministério da Saúde se reúne com representantes de 5 vacinas contra covid. UOL Notícias 2020; 22 nov. https://noti cias.uol.com.br/saude/ultimas-oticias/reda cao/2020/11/22/ministerio-da-saude-se-reu ne-com-representantes-de-5-vacinas-contracovid.htm.

8. Rossini MC. Qual deve ser a eficácia de uma vacina contra a Covid-19? Super Interessante 2020; 11 nov. https://super.abril.com.br/cien cia/qual-deve-ser-a-eficacia-de-uma-vacina/ https://super.abril.com.br/ciencia/qual-deveser-a-eficacia-de-uma-vacina/.

9. Ansede M, Galocha A, Oliveira R. As diferenças abismais entre as vacinas de Oxford, Pfizer e Moderna, a Coronavac e a Sputnik V. El País 2020; 24 nov. https://brasil.elpais.com/cien cia/2020-11-24/as-diferencas-abismais-en tre-as-vacinas-da-oxford-pfizer-moderna-acoronavac-e-a-sputnik-v.html?ssm=whatsapp.

10. Lacerda CD, Chaimovich H. O que é imunidade de rebanho e quais as implicações? Jornal da USP 2020; 6 ago. https://jornal.usp.br/arti gos/o-que-e-imunidade-de-rebanho-e-quaisas-implicacoes/. 